\title{
РЕЦЕПЦИЯ ФИЛОСОФСКИХ ИДЕЙ В ПАРАДИГМЕ ПРАВОВОГО НИГИЛИЗМА
}

\section{RECEPTION OF PHILOSOPHICAL IDEAS IN THE PARADIGM OF LEGAL NIHILISM}

S. Sirin

Summary: The article examines in detail the philosophical ideas concerning legal nihilism as a negative social phenomenon and a deviant form of social consciousness. Definitions of the main approaches to understanding legal nihilism are given and three levels of legal nihilism are identified: General social, nihilism of individual social structures, legal nihilism of the individual.

Keywords: legal nihilism, social causes, society, state, public consciousness, reception, law.

\author{
Сирин Сергей Анатольевич \\ К.ф.н., доцент, Иркутский государственный \\ медицинский университет \\ tkocmina@gmail.com
}

Аннотация: В статье детально исследуется философские идеи относительно правового нигилизма как негативного социального явления и девиантной формы общественного сознания. Даны определения основных подходов к пониманию правового нигилизма и выделены три уровня правового нигилизма: общесоциальный, нигилизм отдельных социальных структур, правовой нигилизм личности.

Ключевые слова: правовой нигилизм, социальные причины, общество, государство, общественное сознание, рецепция, право.
И сследование теоретических основ явления нигилизма в целом, его причин, этапов формирования и сфер проявления, позволило определить основные направления для исследования правового нигилизма, как одного из его разновидностей, поскольку в современном обществе возрастает роль права как важнейшего регулятора общественных отношений. C обострением экономического, социального и политического кризиса усиливается критика государственной власти; такая ситуация приводит к распространению политического и правового нигилизма. Необходимость анализа данного явления всё чаще встаёт перед учеными исследователями проблемы.

Вместе с развитием общества правовой нигилизм приобретает новые формы проявления, меняются его природа, причины и сферы влияния. Нигилизм становится присущим не только «народу», но и властным «верхушкам», проявляется в форсировании социальных преобразований, желании достичь изменений не в результате постепенного реформирования и улучшения, а путем популизма и демагогии. Такое положение вещей приводит к двойному или «двустороннему», нигилизму в обществе.

Впервые нигилистические идеи о праве выдвинули конфуцианцы в Китае, которые в отличие от античной социально-политической мысли, подчеркивающей важную роль права и законов (Аристотель, Платон и др.), утверждали, что обществом следует управлять не с помощью законов, а на основе системы традиционных нравственных установок и норм этикета [2].

Несмотря на то, что на данном этапе развития юриди- ческой науки понятие правового нигилизма заняло соответствующее место среди других правовых категорий, единственное и общепринятое определение данного явления отсутствует. Анализируя основные современные дефиниции исследуемого явления, следует обратить внимание на следующие:

1. Правовой нигилизм - направление общественнополитической мысли, что отрицает социальную ценность права и считает его менее совершенным способом регулирования общественных отношений;

2. Правовой нигилизм - направление политикоправовой мысли, который отвергает социальную ценность права и культивируют негативное отношение к нему;

3. Правовой нигилизм - разновидность деформации правосознания, отрицание или игнорирование права, негативное отношение к нему; антипод правовой культуры;

4. Правовой нигилизм - разновидность социального нигилизма, который, с одной стороны, можно рассматривать как состояние общества, а с другой как личностные убеждения отдельных субъектов, находящих проявление в соответствующих действиях, через неуважительное отношение к праву, законам, правопорядку, пренебрежение правовых ценностей и традиций;

5. Правовой нигилизм - негативное социальное явление, девиантная форма общественного сознания, характеризующаяся совокупностью чувств, настроений и эмоций по поводу отрицания правовых форм регулирования жизни общества и наличием альтернативных идей и способов организации общественных отношений [8, с.3]. 
Анализ литературы явно указывает на то, что определение основного (базового) понятия основывается на использовании достаточно разных по сути категориальных «привязок», ещё разнообразие является состав содержания понятия правового нигилизма. Как отмечает О.В. Дручек, коэволюционные (параллельные) определение понятия правового нигилизма отличаются впечатляюще. Так, дополнительные дефиниции этого термина являются такими: это - «направление общественно-политической мысли» [2], крайнее проявление правового невежеством или «бескультурье»; деформированное состояние правосознания личности, общества, социальной группы; «патология правового сознания» [12], «невостребованность права обществом» [15], «теория и практика отрицания права обществом» [10]. Из указанного следует факт существования различных методологических подходов к суждению о сущности правового нигилизма. Одним из путей качественного вывода понятия правового нигилизма является изучение и применение этих подходов к его пониманию.

На основе общетеоретической методологии изучения права предлагаем выделить следующие подходы к пониманию правового нигилизма: этимологический, психологический (эмпирический), идеологический (аксиологический), феноменологический, интеграчионный (коммуникативный).

В современной научной литературе можно обнаружить два основных подхода к пониманию сущности правового нигилизма -классический (или традиционный) и новаторский. В рамках традиционного подхода правовой нигилизм рассматривается как деструктивный социальный феномен, сущность которого - отрицательное отношение к праву, неверие в его возможности решать насущные проблемы в соответствии с социальной справедливостью. Общественно-политический деятель, писатель А.И. Герцен еще в середине XIX в. отмечал, что нигилизм является логикой без структуры, наукой без догматов, это безусловное подчинение опыта и смиренное восприятие его последствий. А.И. Герцен рассматривал данное явление как черту, присущую общественному сознанию и национальной психологии русского народа, особенность культуры и традиций [3]. Другой представитель классического подхода В.О. Лучин, уже в XX в., обращает внимание на то, что «правовой нигилизм не следует интерпретировать как врожденную черту советского народа, хотя он действительно связан с существующим в обществе укладом и отражает многие его негативные составляющие...» [6]. Конечно, чувства отторжения права появляется не с момента рождения, а формируется у лица со временем, при отсутствии положительных результатов взаимодействия с правовыми нормами. Нигилистами, как и преступниками, не рождаются, ими становятся [5]. Но нельзя отрицать и тот факт, что в настоящее время нигилизм стал характерной осо-

\section{бенностью менталитета.}

Представители новаторского подхода к пониманию правового нигилизма обосновывают мысль о его позитивности или тезис о том, что к существованию данного явления приводит само право через своё несовершенство. Правовой нигилизм рассматривается как специфический социальный ориентир, указывающий направление негативных тенденций в юридической сфере и без которого становится невозможным поиск новых концепций и идеалов, а также путей решения существующих в обществе проблем.

Заметим, что нами не отрицаются определенные положительные проявления правового нигилизма, как толчка к поиску новых концепций и идеалов, однако в своем классическом смысле он является деструктивным явлением и отрицает существующие порядки, в конечном счете, не создав ни одной положительной программы действий.

На уровне массового и группового сознания правовой нигилизм определяется как обобщенное устойчивое социальное наставление, которое состоит из многих индивидуальных (персонифицированных) наставлений. Это как обратная психологическая реакция на внешние раздражители со стороны субъектов права и всего общества в целом [13]. Многократные «столкновения» граждан с нормами права, которые не принесли желаемых результатов, формируют негативное отношение как к должностным лицам, которые применяют те или иные предписания, так их к самим этим предписанием.

Несмотря на различные толкования, определения и дефиниции категории правового нигилизма, учёные отмечают, что это явление является результатом определенной деформации правового сознания на определенном историческом этапе развития общества.

Учитывая изложенное, предлагается рассматривать правовой нигилизм, как направление общественно-правовой мысли, что возникает на определенном историческом этапе развития общества, особенно усиливаясь в кризисные периоды, который отвергает социальную ценность права, культивирует негативное отношение к нему и относится к стойким проявлениям деформации правосознания населения, отрицая действующие правовые нормы и не предлагая взамен ничего нового. Такое отношение к праву является безосновательным и умышленным унижением его положительной роли. Характерным признаком данного явления является категоричность и бескомпромиссность отрицания, доминирование субъективных начал с гипертрофированными, демонстративно преувеличенными сомнениями в общепринятых правовых нормах и ценностях. 
Однако следует отметить, что несовершенство и противоречивость норм права, вызывая их нигилистической оценку, становится источником и движущей силой для поиска новых правовых решений. Низкая степень отторжение обществом норм права подтверждает профессионализм законодательных и исполнительных органов власти. Это так называемая обратная связь, оценка населением работы властных структур и их реальных действий. Российская исследовательница правового нигилизма О.Р. Гулина отмечает, что «степень правового нигилизма является своего рода «лакмусовой бумажкой», признаком здоровья общества и государства» [4]. С этой позиции правовой нигилизм можно рассматривать как специфический социальный ориентир, указывающий направление для устранения негативных тенденций в государственно-правовой сфере.

Пренебрежительное и высокомерное восприятие права, оценка его как второстепенного явления в общей шкале человеческих ценностей, характеризует меру цивилизованности общества, состояние его духа, мировоззрения, социальных привычек. Устойчивое неверие в высокое предназначение, потенциал, универсальность права является морально-психологическим генезисом правового нигилизма. Кроме того, оказывает влияние отсутствие необходимого правового опыта, навыков, грамотности, материальной базы.

Правовой нигилизм оценивается исследователями как опасное социальное явление, охватившее все уровни общественных отношений - от повседневного общения между людьми к сфере деятельности законодательных органов власти. О.Р. Гулина подчеркивает, что правовой нигилизм - это не только правовая категория, но и реально существующее социально-психологическое явление, отражающее политические и национально-исторические особенности общества. Как линия, он проходит через действия всех центральных органов власти, политическое и правовое сознание, поведение граждан [4]. Этот феномен находит своё проявление в любых нарушениях закона, пренебрежительном отношении к праву и его роли в обществе, в наличие законов и нормативно-правовых актах, что противоречат друг другу, то есть в определённых асоциальных их и антисоциальных фактах. В.И. Червонюк, изучая эту проблематику, выделяет три уровня правового нигилизма:

- общесоциальный, для которого характерно отрицание идеи верховенства права на уровне всей социальной системы и её управленческих структур;

- нигилизм отдельных социальных структур - государственных и негосударственных, формальных и неформальных;

- правовой нигилизм личности [16].

Необходимо отметить, что распространение право- вого нигилизма на общесоциальном уровне означает, что государство как управляющая система попирает право или использует его как средство ограничения индивидуальной свободы граждан. В таком случае отношения строятся на основе властных предписаний, которые принудительно насаждаются «сверху»; все права власть концентрирует в «своих руках», возлагая на население обязанность выполнять собственные предписания. Издание большого количества законов, которые не имеют механизмов реализации и произвола чиновников, которые толкуют такие законы с выгодой для себя, приводит к распространению в обществе не только правового нигилизма, но и правового отчуждения и индифферентности, поскольку население, разуверившись в возможностях права, занимает позицию равнодушия. Происходит отторжение гражданами права как социально ценностного института, теряется интерес к нему и уменьшается авторитет. Такая ситуация в основном присущая недемократическим государственным режимам, поскольку является необходимым атрибутом административно-командной системы.

В массовом сознании граждан можно проследить двойное восприятие роли государства, которое, с одной стороны, выступает в качестве силы, способной защитить от бюрократии и криминала, а с другой - не вызывает у населения доверия, насаждая контроль и ограничения. А в сочетании с накоплением большого количества законов без механизмов их реализации вызывает негативное отношение к ним и к государству в целом. К тому же существуют случаи, когда правовой нигилизм провоцирует само государство, ставя человека в условия, когда на одной стороне весов оказывается соблюдение законодательства, а на втором - достойный уровень жизни, поскольку закрепленные в конституции права человека и гражданина ущемляются нормативными актами. Однако и в такой ситуации человек с высоким уровнем правовой культуры отдаст предпочтение законным способам опротестования упомянутых норм.

На уровне отдельных социальных структур и личностном правовой нигилизм, к сожалению, также распространён, поскольку в наше время правовые отклонения в поведении граждан и должностных лиц стали обычным явлением. Следует отметить, что склонность поддаться разрушительному действию правового нигилизма, прежде всего, зависит от развития морально-волевых качеств личности. Чем сильнее воля, тем легче противостоять, не поддаваясь нигилистическим настроениям. В таком случае многое зависит и от активной позиции государства по искоренению правового нигилизма, действенными мерами являются системные программы по повышению уровня правовой культуры граждан и авторитета права, подготовка высококвалифицированных кадров юристов, воспитания у них уважения к букве закона. 
Три указанных уровня правового нигилизма связаны между собой, хотя есть и относительно автономными. Это означает, что не существует фатальной неизбежности подвергнуться разрушительному воздействию данного явления, даже находясь в зоне его активного проявления, к тому же изменении ситуации на одном из уровней, на других может не состояться чувствительных преобразований [16].

Правовой нигилизм стал характерной особенностью менталитета, а потому для полного и всестороннего исследования данного явления следует рассмотреть понятие правового менталитета и его признаки.

Правовой менталитет представляет собой совокупность осознанных и неосознанных психологических установок и склонностей индивида действовать, мыслить, чувствовать, воспринимать и постигать различные явления определённым образом, оценивая их как положительные или отрицательные в государственно-правовой сфере [11]. Правовой менталитет находится в тесной связи с такими понятиями, как «правосознание» и «правовая культура», но является более фундаментальным и глубинным социально-психологическим явлением, которое не поддается быстрым изменениям; включает в себя исходные этические и культурно-исторические основы национальный правовой культуры. Политическое и идеологическое влияние на него с целью радикальных преобразований в короткий срок неэффективно и приводит лишь к внешним, поверхностным изменениям, а потому государство должно осуществлять постепенные, глубинные программы по повышению уровня правового образования населения и правовой социализации (на всех уровнях и во всех социальных группах, начиная со школьного возраста). Только такие меры получат положительный долгосрочный эффект.

Следует отметить, что в обществе индивид часто не обладает достаточным уровнем чувства положительной правовой ответственности и долга, которое характерно для граждан западноевропейских демократий, что значительно усложняет отечественный правовой прогресс в его западном понимании. Из-за политической демагогии и наивной веры народа в популистские лозунги и призывы наша правовая ментальность оказывается слишком политизированной, совмещённой с идеологической сумбурностью (неразберихой) и изменчивостью экономических, политических и правовых ориентиров. К этому времени обществу не ясны стратегические цели государственного развития, часто власть не дает четкого, конкретного ответа на главные вопросы, что порождает неверие народа в добросовестность и эффективность власти. В такой ситуации для многих граждан альтернативой праву в регулировании общественных отношений выступают личные связи, которые, к сожалению, оказываются для участников более эффективными, чем нормы права. Все эти явления напрямую связаны с правовым нигилизмом, который, развиваясь на фоне бюрократии и коррупции, вытесняет право из многих сфер нашей жизни.

Правовой нигилизм можно рассматривать и как деструктивную особенность психологии личности. Негативная реакция на законодательные установки, несоблюдение общеобязательных правил поведения, а иногда грубое их нарушение, способно не только затормозить развитие прогрессивных тенденций, но и разрушить уже достигнутые положительные результаты.

В современном обществе термин «правовое нигилизм» употребляют при характеристике неблагоприятной ситуации, сложившейся в сфере права, данная категория имеет отрицательный смысл, однако для всестороннего исследования правовой нигилизм следует отличать от двух близких ему понятий: правового инфантилизма и критики права [5].

Инфантилизм (от лат. Infantilis - детский) - coхранение у взрослых лиц физических и психологических черт, присущих более раннему (детскому или подростковому) возрасту. Инфантильный нигилизм является формой деформации правосознания, которая характеризуется правовой незрелостью личности, повышенной несамостоятельностью, отсутствием чувства долга и ответственности, распространен преимущественно среди подростков и школьников. Одной из черт, присущих современной молодёжи, является инстинкт толпы. Ставь её частью, лицо будто снимает с себя ответственность за происходящее вокруг, растворяясь в общей массе. Действиями каждого из участников управляют не собственные чувства, а поведение толпы, личные моральные установки при этом отсутствуют. Поэтому большинство показательно противоправных, хулиганских, бессмысленных поступков совершают именно группы лиц. Кроме того, молодёжи присущи такие качества, как максимализм, агрессивность и нетерпимость. Эти качества являются ответной реакцией на ограничения «абсолютной свободы личности», которой, как известно, не существует [14]. А поскольку в роли ограничителя выступает право, появляется стремление его отторгнуть и поступить вопреки устоявшимся общественным, моральным и правовым нормам.

Говоря о критике права, имеется в виду критика положительная и научно обоснованная, как правило, она является конструктивной и содержит конкретные практические рекомендации по совершенствованию правовых институтов. А правовой нигилизм не связан с какими-либо обоснованиями и доказательствами, это игнорирование правовых ценностей, отсутствие какойлибо позитивной программы преобразований. Критика права отличается от правового нигилизма и своей опре- 
деленностью, четкостью, её объектом выступают конкретные положения законодательства (законы, статьи, коллизии и пробелы в праве и т.д.), тогда как нигилизм отвергает право в целом, без учета его негативных и положительных черт. К тому же критика права направлена на улучшение ситуации и исключает ухудшение социальных обстоятельств, а правовой нигилизм в полной мере способствует последнему.

Среди исследователей данного явления нет единого мнения о том, что именно отрицается правовым нигилизмом. А.В. Арбузов отмечает, что объектом деформации со стороны правового нигилизма выступает право как система [1]. М.А. Месилов не согласен с такой позицией, считая, что отрицаются три вещи: действующее законодательство, правопорядок, базовые идеи и принципы законодательного регулирования [9]. Д.Э. Марченко отмечает, что с позиций юридического позитивизма, правовым нигилизмом отрицаются любые декларируемые законом ценности и нормы права, а с позиции естественного права - основополагающие принципы и ценности права, такие как равенство, свобода, справедливость и др. [7] Характерными признаками такого возражения являются его степень, интенсивность, бескомпромиссность, категоричность и «живучесть». Последнюю следует выделить особенно, поскольку правовой нигилизм может периодически «исчезать» со страниц печатных и научных изданий, внимание ученых и публицистов к нему может ослабевать по мере появления неотложных жизненных проблем, но в реальной жизни пренебрежение и неуважение к праву, к сожалению, остаются.

Следует отметить, что правовой нигилизм отрицает целый комплекс не только положительных, но и негативных явлений действительности, например, норм права, отживших или не оправдавших себя. Для того, чтобы полностью раскрыть объект отрицания, недостаточно использовать термин «право» как отдельно взятую категорию. Правовой нигилизм имеет много проявлений, поэтому отрицаются такие вещи, как социальная ценность права и основополагающие правовые ценности, существующая правовая система и система законодательства, правовые нормы и предписания, права человека и гражданина.

\section{ЛИТЕРАТУРА}

1. Арбузов А.В. Правовой нигилизм: теоретико-правовое исследование: дис. ... канд. юрид. наук: 12.00 .01 / Арбузов Анатолий Валерьевич. - С.-Пб., 2006. - 209 с.

2. Большая Советская Энциклопедия: в 30 т. / [под ред. А.М. Прохорова]. - 3-е. изд. - М.: Советская Энциклопедия, 1974-1978. - Т. 17: Моршин-Никиш. 1974. -615 с.: илл.

3. Герцен А.И. Собрание сочинений: в 8 т. / Герцен А.И.; [под ред. С.И. Машинского]. - М.: Правда, 1975.- Т. 8: Избранные публицистические произведения 1853-1869 годов. $-1975 .-447$.

4. Гулина 0.Р. Исторические корни и особенности правового нигилизма в современной России: автореф. дис. на соискание науч. степени канд. юрид. наук: спец. 12.00.01 «Теория и история права и государства; история правовых учений» / 0.Р. Гулина. - Уфа, 2002. - 30 с.

5. Зрячкин А.Н. Правовой нигилизм: причины и пути их преодоления: дис. ... канд. юрид. наук: 12.00.01 / Зрячкин Александр Николаевич. - Саратов, 2007. - 187 с.

6. Лучин В.О. Конституция Российской Федерации. Проблемы реализации / Лучин В.0. - М.: Юнити, 2002. - 687 с.

7. Марченко Д.Э. Правовой нигилизм, правовой идеализм и правовой инфантилизм как формы деаксиологического правового сознания: [монография] / Марченко Д.Э. - Самара: НТЦ, 2006. - 114 с.

8. Матузов Н.И. Правовой нигилизм и правовой идеализм как две стороны одной медали / Н.И. Матузов // Правоведение. - М., 1994. - № 2. - С. $37-46$.

9. Месилов М.А. Правовой нигилизм: учебн. пособ. / Максим Александрович Месилов / [общ. ред. А.П. Печников]. - М.: Моск. городск. ун-т управления Правительства Москвы, 2006. - 48 с.

10. Поляков А.В. Общая теория права: Феноменолого-коммуникативный подход: [курс лекций] / Поляков А.В.; - [2-е изд., доп.]. - С.-Пб. : Юрид. центр Пресс, 2003. $-856 \mathrm{c}$.

11. Проблемы теории государства и права: учебн. / [Т.В. Кашанина, Н.А. Власенко, В.В. Лапаева и др.]; под. ред. В.М. Сырых. - М.: Эксмо, 2008. - 528 с.

12. Протасов В.Н. Теория права и государства. Проблемы теории права и государства: Вопросы и ответы / Протасов В. Н. - М.: Новый Юрист, 1999. - 240 с.

13. Сазонов В.Г. Понятие правового нигилизма / В.Г. Сазонов // Государство и право. - М., 2004. - № 12. - С. 66-70. Субботин В.

14. Субботин В. Зла не хватает? // Человек: Архитектура души. Психология личности. Мир взаимоотношений. Психотерапия / В. Субботин. - М.: Аванта, 2002. - С. 160-168.

15. Теория государства и права: курс лекций / [под ред. Н.И. Матузова, А.В. Малько]. - М.: Юристь, 2019. - 672 с.

16. Червонюк В.И. Теория государства и права / Червонюк В.И. - М.: Инфра-М, 2016. - 704 с.

(c) Сирин Сергей Анатольевич (tkocmina@gmail.com).

Журнал «Современная наука: актуальные проблемы теории и практики» 